\title{
A Longitudinal View of Look at the Effectiveness of Elicited Imitation with Computer Assisted Pronunciation Training (CAPT)
}

\author{
Liwei Hsu (Corresponding author) \\ Professor, National Kaohsiung University of Hospitality and Tourism \\ No. 1, Sunghe Rd., Hsiao-Kang District, Kaohsiung City, Taiwan \\ Tel: 886-78060505Ｅ-mail: liweihsu@mail.nkuht.edu.tw
}

Received: February 17, 2016 Accepted: March 3, 2016 Published: March 28, 2016

doi:10.5296/ire.v4i1.9033 URL: http://dx.doi.org/10.5296/ire.v4i1.9033

\begin{abstract}
It is the aim for most EFL learners to have a clear pronunciation in English; however, pronunciation training has always been a challenge for EFL teachers and learners alike. The advent of Computer Assisted Pronunciation Training (CAPT) seems to be the solution to this problem. This longitudinal study adopted a latent growth curve to describe 30 EFL learner's (N = 30) development of imitated pronunciation in English as well as their satisfaction regarding CAPT. These 30 participants were randomly assigned to the experimental group $(\mathrm{N}=18)$ and control group $(\mathrm{N}=12)$. There were no significant differences among the participants in their pronunciation of English or attitudes toward CAPT at the beginning of this study. After 16 months of training, the growth curve analysis showed that participants in the CAPT group made significantly greater development in English pronunciation, and they were more satisfied with the CAPT. The large effect size indicated that the grouping was the major effect that led to a significant difference in satisfaction. Moreover, the qualitative dlata derived from focus-group interviews confirmed the benefits of CAPT in participant's pronunciation training. These findings suggest that EFL learner's opportunities to conduct elicited imitation with the help of ASR-CAPT will be helpful for their development of imitated pronunciation in English and increase their satisfaction of it, which is a key aspect in the effectiveness of pronunciation training.
\end{abstract}

Keywords: EFL learning, elicited imitation, Computer Aided Pronunciation Training (CAPT), linear growth curve, learning satisfaction 


\section{Introduction}

Pronunciation is a crucial element of successful communication (Tsai, 2006); therefore, a clear pronunciation seems advantageous to effective communication (Celce-Murcia, Brinton, \& Goodwin, 2010; Gilakjani, 2012; Hismanoglu \& Hismanoglu, 2010; Jenkins, 2002). Nevertheless, most language learners view pronunciation as the most difficult skill to acquire while learning the target language (Neri, Cucchiarini, \& Strik, 2006), and English pronunciation is often given the least amount of attention by many EFL teachers (Darabad, 2014; Nair, Krishnasamy, \& De Mello, 2006). From the perspective of teaching, some teachers argue that they do not know how to teach pronunciation (MacDonald, 2002). One possible reason pointed out by Breitkreutz, Derwing, and Rossiter (2002) was that many of EFL teachers did not receive pertinent training on pronunciation instruction. Nevertheless, they explicitly stated that formal instruction in pronunciation had a long-term and positive effect on one's pronunciation.

Regarding the mechanisms used for learning pronunciation, imitation is one of them (Darabad, 2014), and elicited imitation can be used as a reconstructive technique (Jessop, Suzuki, \& Tomita, 2007) by providing learners with corrective feedback about their pronunciation. Recently, Computer Assisted Pronunciation Training (CAPT) has become prevalent in the EFL context (Heish, Dong, \& Wang, 2013; Levis, 2007; Seferoğlu, 2005; Thomson, 2011; Wang \& Munro, 2004). EFL learners who have limited access to English or to their teachers can benefit from the additional assistance provided by the system. However, CAPT remains in its infancy, and additional empirical support regarding its effectiveness is needed (Thomson, 2011). This study addresses this research gap and examines the applicability of CAPT to EFL pronunciation training through longitudinal research design. Three research questions are to be answered in the current study:

1) What is the longitudinal trajectory of the pronunciation of English of EFL learners who practice elicited imitation (EI) with CAPT?

2) What are EFL learner's perceptions of corrective feedback provided by the CAPT systems regarding their English pronunciation training?

3) How satisfied are EFL learners with CAPT and its correlation on their development of pronunciation in English?

\section{Literature Review}

\subsection{CAPT for EFL Learning}

CAPT is a subset of Computer Assisted Language Learning (CALL) that can substantially aid EFL learning (Godwin-Jones, 2009; Levis, 2007), as it provides explicit intervention (Akakura, 2012; Thomson, 2011) by creating a meaningful, interactive, and flexible language environment (Chen, Zhang, \& Liu, 2014). Additionally, CALL features a functionality that is difficult to offer in the traditional context: immediate feedback with visual displays of the pitch and movements of articulators (Kim, 2012).

Despite the positive results of previous studies and CALL's popularity in practice, CALL is not perfect for EFL learners in all domains or all conditions of language learning (Chen, 
Belkada, \& Okamoto, 2004), particularly in pronunciation learning. Most CALL programmes are not specifically for pronunciation training; however, automatic-speech-recognition (ASR) technologies have developed rapidly in recent years (Barr et al., 2005). Although possibly less accurate than a human listener, current ASR software is sufficiently accurate to be useful in the pronunciation training of EFL learners (Chun, 2007; Godwin-Jones, 2009; Hincks, 2003; Penning de Vries, Cucchiarini, Bodna, Strik, \& van Hout, 2014). Recently, the adoption of CAPT has altered the landscape of teaching pronunciation to EFL learners. It has also become a popular academic research topic (Chiu, Liou, \& Yeh, 2007; Levis \& Pickering, 2004).

Prior research has found CAPT to be an effective tool in assisting EFL learners in acquiring correct pronunciation (Felps, Bortfeld \& Gutierrez-Osuna, 2009; Lambacher, 1999; Murphy, 2014; Neri et al., 2006) as it enables autonomous learning of EFL learners through abundant, realistic, and contextualised spoken examples, using a multimedia model (Chiu et al., 2007; Neri, Cucchiarini, \& Strik, 2008; Neri, Mich, Gerosa, \& Giuliani, 2008). In particular, corrective feedback through CAPT helps EFL learners improve their pronunciation of English (Chun, 2007; Lyster, Saito, \& Sato, 2013; Neri et al., 2008) because the state-of-art ASR-based CAPT can provide them with feedback at phoneme, word, and/or sentence levels (Neri et al., 2008). Another advantage of CAPT is that it can address the varying needs of individual learners that result from differing levels of English proficiency (Chiu et al., 2007; Godwin-Jones, 2009; Jepson, 2005).

However, the application of CAPT may not always result in improvements, and it remains uncertain to what extent CAPT can benefit pronunciation training (Thomson, 2011). For example, Neri et al. (2006), and Mich, Neri, and Giuliani (2006), noted that CAPT did not seem to be very promising for pronunciation training, nor was it found to be superior in helping learners acquire intelligible pronunciation. Although prior studies, using small samples (Chiu et al., 2007; Neri et al., 2006, 2008), have adopted experimental designs to examine the pedagogical effectiveness of ASR-based CAPT, such studies have not persuasively demonstrated how CAPT could be helpful to learners (Chiu et al., 2007). The possible uses of CAPT in EFL learning remain under-examined (Neri et al., 2008). Further exploration of CAPT's pedagogical effectiveness, using longitudinal data, could fill this research gap.

\subsection{Elicited Imitation for Pronunciation Training}

Imitation is a basic human learning mechanism. For language learning, pronunciation can be partially learned through imitation, which is conducted through the input-feedback-output process (Darabad, 2014). Without proper feedback, learners may fail to convert input into intake. McDonough (2005) highlighted the output of learners, modified by corrective feedback, as the foundation of L2 development. In the present study, the EI technique is introduced as an explicit intervention into EFL learner output, which is modified by corrective feedback. In recent decades, EI has been used to measure the performance of a learner in second-language acquisition (Cook \& McGhee, 2011). The technique is administered by asking a learner to produce an oral repetition of an utterance to the instructor 
as exactly as possible. In an EI framework, corrective feedback is a critical ingredient. More importantly, when EFL learners are explicitly instructed to focus on the stress and intonation of English, their pronunciation would improve (Field, 2005; Yanglang, 2013).

The adoption of EI in EFL learning indicates that EI is understood as reconstructive (not simply as rote repetition) and as an activity that conveys valuable information to the teacher or learner (Jessop et al., 2007). Furthermore, EI is well suited to the CALL context (Graham, Lonsdale, Kennington, Johnson, \& McGhee, 2008), particularly when the technology can provide learners with meaningful feedback that contributes to improved pronunciation in the target language (Chun, 2007). Despite this empirical evidence, providing results of another academic work to extend our current understanding about EI or CAPT could be a worthwhile contribution to CALL.

\subsection{Learner Satisfaction and CAPT}

Learner satisfaction with online learning systems refers to a learner's willingness to use a system after he or she first experiences it (Levy, 2007). According to researchers, student satisfaction with any type of technology-based programme is determined mainly by the design of the given course along with other factors (Stein, 2004). EFL learners who are satisfied with the functionalities of CALL tend to have positive attitudes toward CALL (Almekhlafi, 2006; Wang \& Munro, 2004). Regarding ASR assistance, which enables a virtual tutor always be available to EFL learners, many empirical studies have demonstrated that learner satisfaction with ASR-based CAPT is positive (Munsakorn, 2012). However, the issue of how EFL learner satisfaction with CAPT affects learning outcomes remains to be explored. This study undertakes such an exploration.

\section{Method}

\subsection{Participants}

Thirty sophomores at a public university in southern Taiwan $(n=30)$ were invited to participate in the research project, and they were randomly assigned to an experimental group (18 participants received CAPT) or a control group (the remaining 12 participants, who did not receive CAPT). To accurately capture the general circumstances of Taiwanese EFL learners, whose access to authentic English-language materials or native speakers is limited, only non-English-major students were selected as participants. This sampling strategy enabled us obtain a better understanding of the effect of CAPT in helping; most EFL learners with pronunciation training (Chen et al., 2014).

The experimental group members were required to spend approximately 1.5 hours per week practicing EI on the ASR-based CAPT system (hereafter as MyET), with their CAPT activities recorded on a monthly basis. The control group was not asked to practice EI but was asked to complete one unit of practice on MyET each month as a means of recording the progress of their pronunciation. MyET also recorded this group's performance. All 30 participants completed this study, and all of them reported having normal hearing. 


\subsection{Research Procedure}

Given the need for longitudinal research to capture the long-term effects of ASR-based CAPT on EFL learner pronunciation training, the study lasted 16 months (January 2013-March 2014). Subsequently, participants were asked to complete a ten-item post-training questionnaire, using a five-point scale (see the appendix for details). The questionnaire's items were administered in Chinese to ensure participant's comprehension, and they were designed to investigate the self-perception of the EFL learners with respect to CAPT. The collected data were statistically analysed using SPSS 21.0 and the longitudinal data were analysed using HLM 7.0.

Afterwards, two focus groups were formed and 10 participants from the experimental group were purposively selected for being interviewed. Their informed consent was collected before the interviews to ensure that the research ethics for qualitative design were followed (Mack, Woodsong, MacQueen, Guest, \& Namey, 2005). Five participants who showed the greatest improvement in performance were in the first focus groups and another five who comparatively made the least progress were in the second group. Interview is the most common method to collect thick qualitative data (Savin-Baden \& Major, 2013), and focus group interviews enable participants to stimulate their memory, ideas, or experiences by listening to others (Bauer \& Gaskell, 2000; Lindlof \& Taylor, 2002). Two focus group interviews were conducted in the March of 2015. These two groups were asked similar semi-structured questions (e.g. 'how do you feel about using MyET in your pronunciation training?' and 'what are the functionalities that you think MyET benefitted you the most and the least in your pronunciation training?'). Each interview session was approximately 60 to 90 minutes long, and the researcher was the moderator in the interview.

\subsection{The Training Programme}

The ASR-based CAPT, MyET, was designed by a private digital education company with a large market share in online English education in Taiwan (please refer to http://www.myet.com/MyETWeb/SubPage.aspx?fn=MyETIntro.htm for details). Chen's (2004) study discovered that pronunciation assessments administered by MyET were significantly correlated to the ones done by human graders. Therefore, more than 50 higher education institutions and approximately 20 high schools in Taiwan have adopted this system for English pronunciation training (Hsieh, Dong, \& Wang, 2013). The author's University purchased this software to provide students with more opportunities for self-regulated pronunciation training. The programme's content was designed to target the phonological properties of English, taking the concept of EI into consideration. Using the programme, activities are conducted through contextualised conversations. Learners first listen to the text recorded by the virtual tutor and then attempt to reproduce the sounds accurately (see Figure 1 for details). The computer assesses the individual's pronunciation according to produced phonetic features of segmental sounds and advises him/her which phoneme(s) need more practice (Figure 2). Such information has been considered as the first step in pronunciation training (Neri et al., 2008). Four aspects are evaluated: phoneme, stress, intonation, and rhythm/timing (Figure 3). Intonation and fluency are the two essential features of the 


\section{Macrothink}

International Research in Education

ISSN 2327-5499

2016, Vol. 4, No. 1

intelligibility of English pronunciation; hence, these features should be the focal point of CAPT (Hardison, 2004).

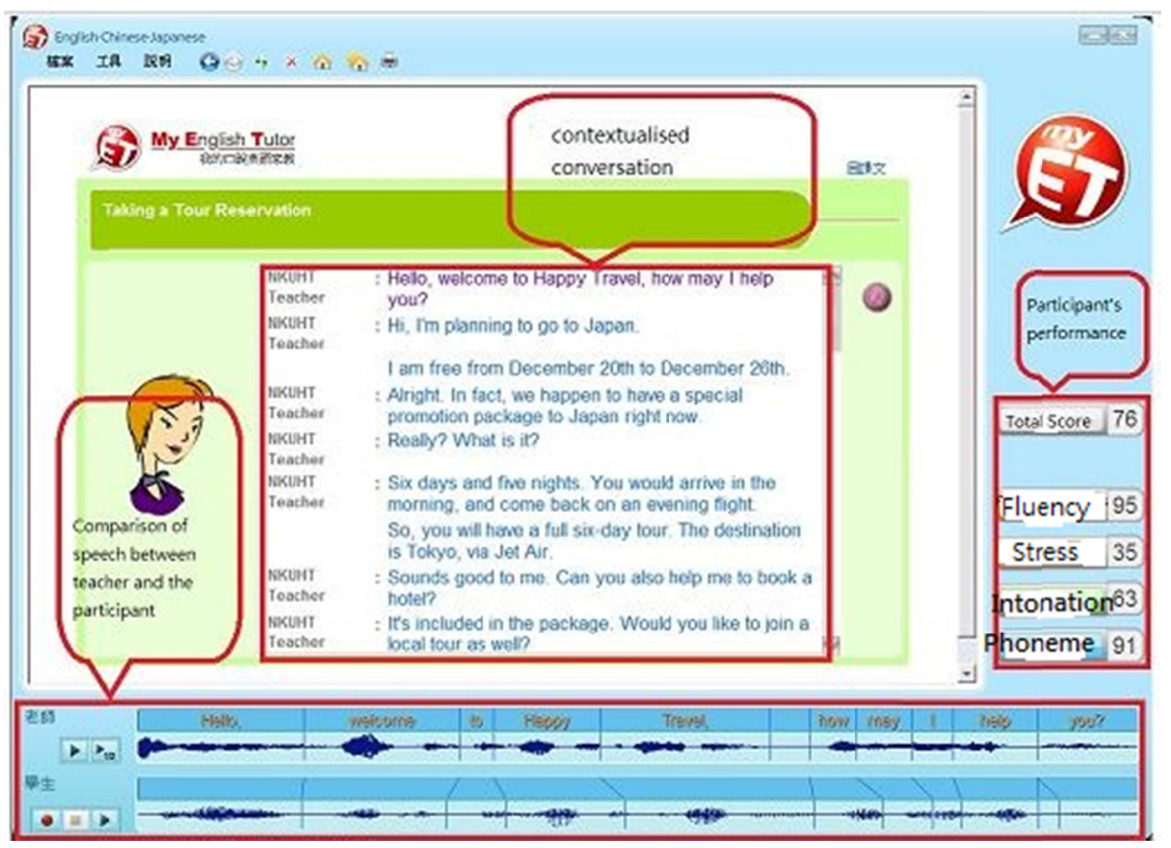

Figure 1. Contextualised conversation of MyET and the functionalities

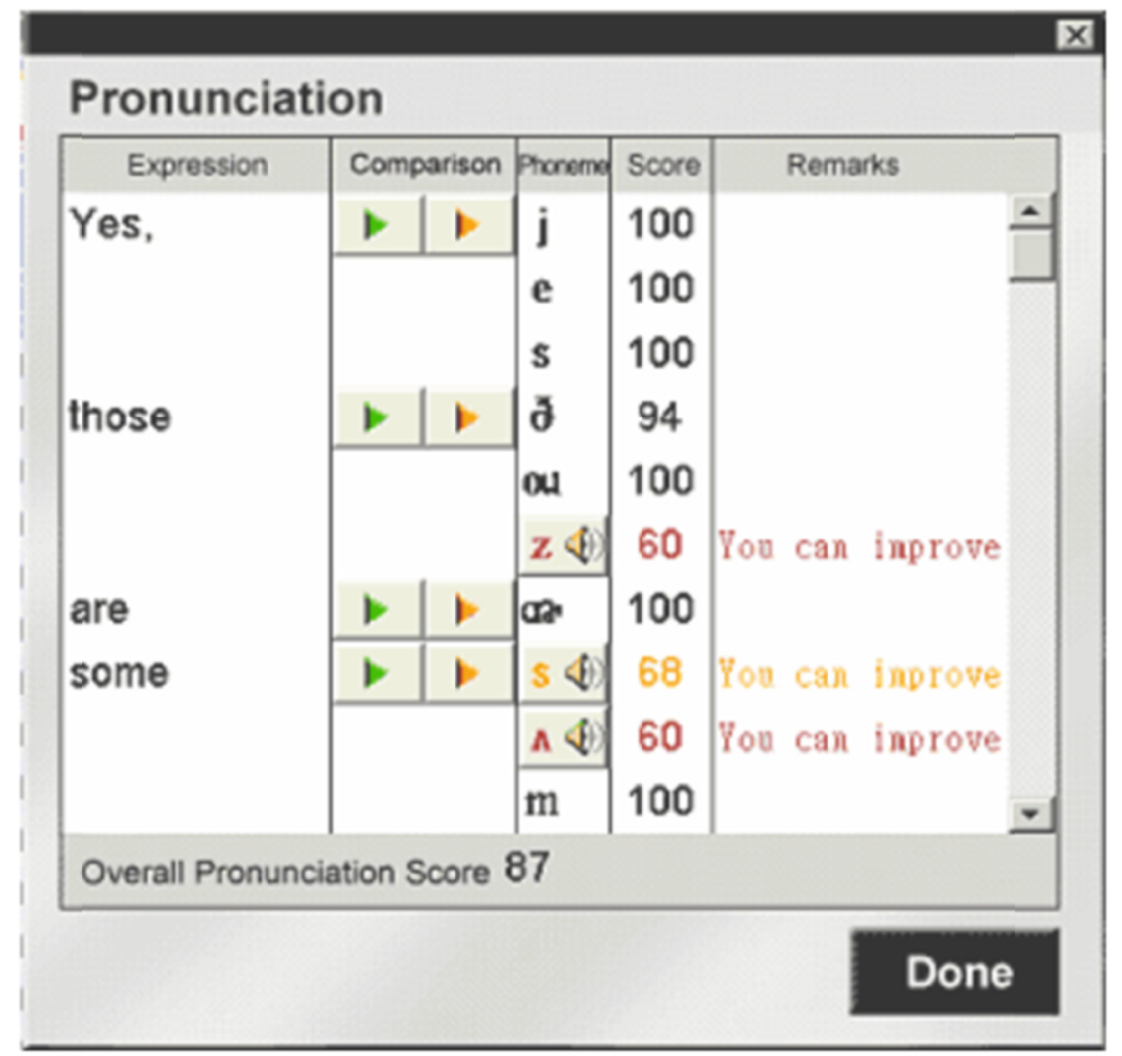

Figure 2. Assessment on participant's phonetic feature of phoneme and suggestions to $\operatorname{him} /$ her 


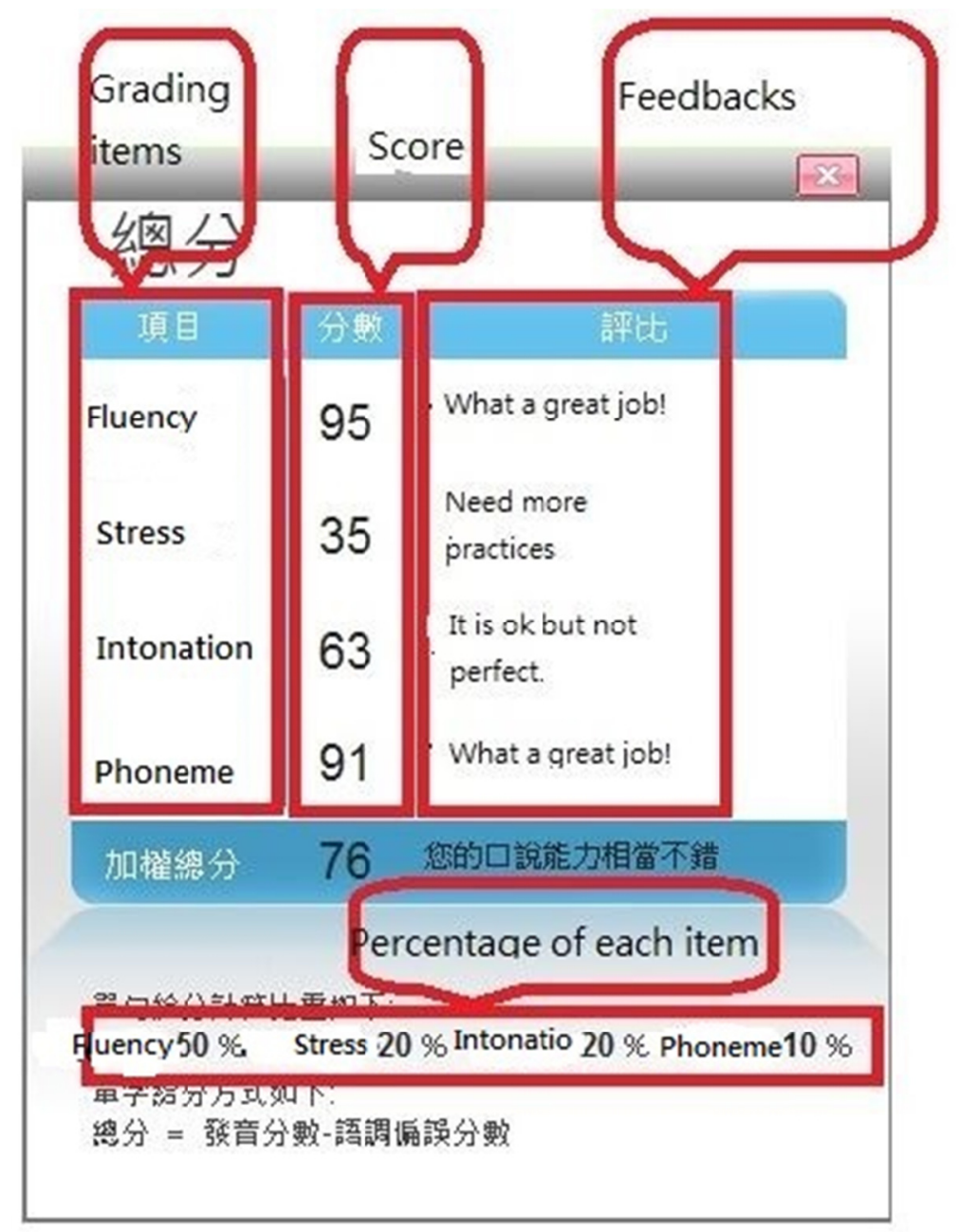

Figure 3. The scoring and feedback provided by MyET

If the ASR algorithm finds that a participant mispronounces a word or phoneme, the system provides the user with corrective feedback on the correct pronunciation accordingly. Specifically, corrective feedback includes the accurate pronunciation of that phoneme which is provided in both visual as well as auditory formats. For example, Figure 4 demonstrates the differences and similarities of sound waves produced by the virtual tutor and the participants. In this way, the participants would be able to correct the stress of the word pronunciation they produce within a sentence. The system can further inform the participants which words are produced with too much emphasis and how their pronunciations deviated from the ones of the virtual tutor (please see Figure 5 for details). More importantly, a pictorial demonstration about the correct position of the vocal organs is presented along with a detailed list of pronunciation method tips (please refer to Figure 6) to direct the learners to the correct pronunciation. 


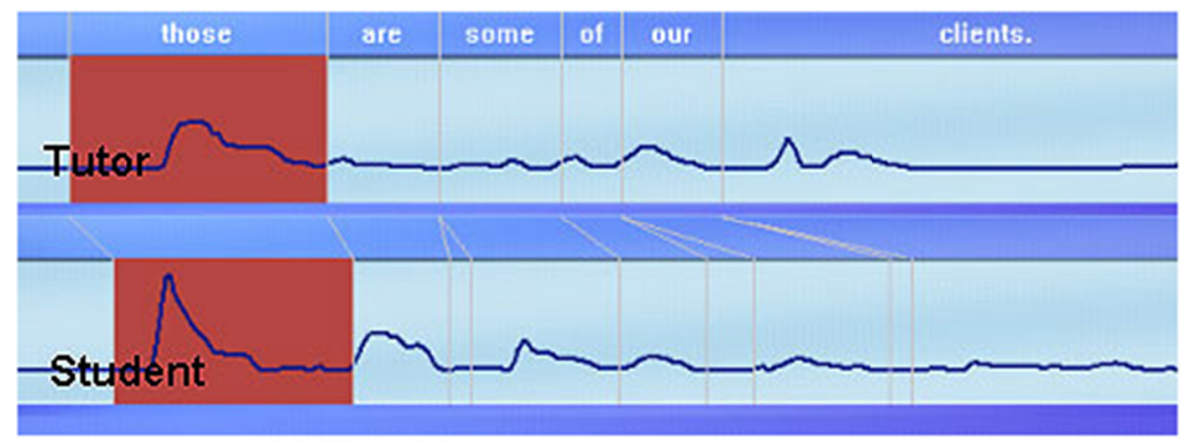

Figure 4. Assessment of participant's stress of English pronunciation. Specific words are marked in red to indicate an error in emphasis. Items marked in orange are errors that are less serious

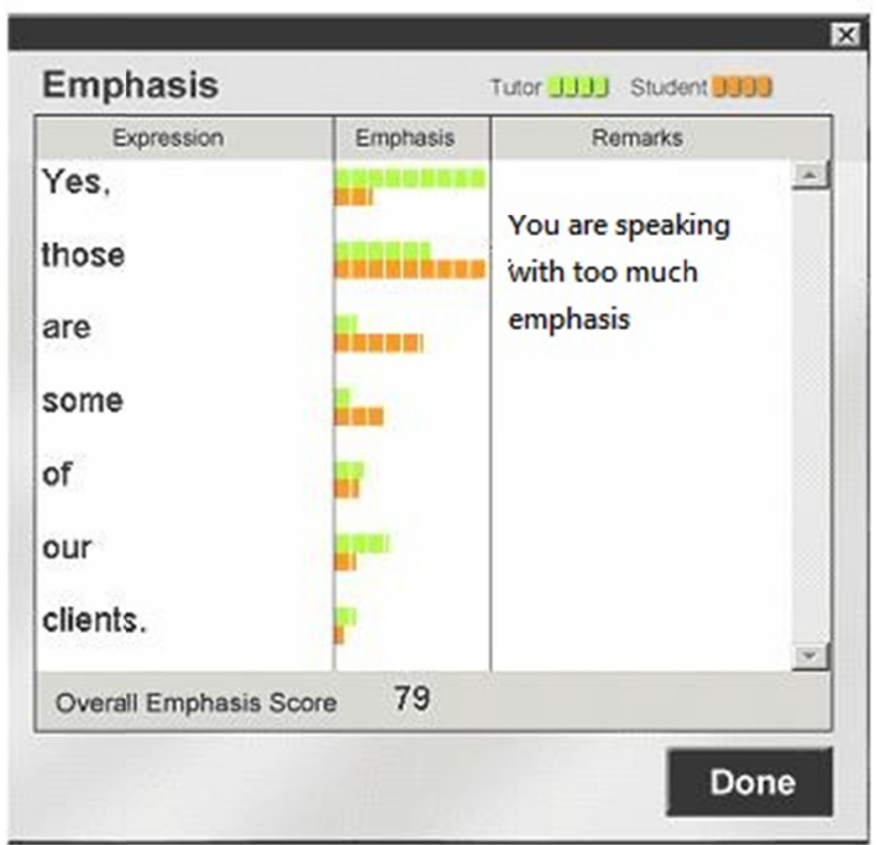

Figure 5. Four aspects of pronunciation are evaluated: phoneme, stress, intonation, and general fluency

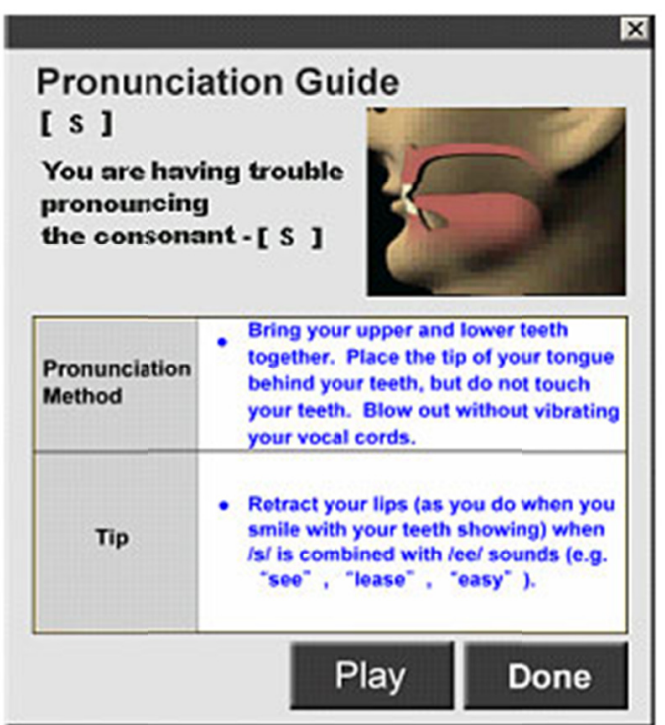

Figure 6. Corrective feedback on participant's mispronunciation and the correct pronunciation

To assure recognition accuracy of MyET, two native-speaker English teachers were invited to test the system. They used MyET to assess their pronunciation of English, and they both found that MyET was able to justify their pronunciation and the feedback provided by the system was linguistically correct and pedagogically constructive. Therefore, they confirmed the system's ability to avoid problematic recognition of user's pronunciation, which could confuse learners (Thomson, 2011; Neri et al., 2008).

\subsection{Data Analysis}

The activities of each participant were recorded and analysed by MyET. A score (on a scale of 
100 points) was assigned to each participant when he or she completed each activity. An average score was calculated for each participant's MyET activities and provided on a monthly basis. This score was used to conduct a Latent Growth Curve (LGC) analysis to answer the first research question. LGC is viewed as having greater statistical power than the repeated ANOVA measure (Osgood \& Smith, 1995; Shek \& Ma, 2011). Furthermore, learning is a continuous process; thus, it is crucial to examine the rate of change of possible variables (Miner \& Clarke-Stewart, 2008, cited in Shek \& Ma, 2011). In the present study, there were 16 waves of longitudinal data, and the large 'number of time points necessitated the use of polynomial models for the individual trajectories' (Francis, Fletcher, Stuebing, Davidson, \& Thompson, 1991, p. 36). Other factors, such as the novelty effect, can also be prevented under the longitudinal LGC design.

The second research question was addressed with qualitative interviews that focused on the participant's viewpoints about the feedback provided by the ASR-based CAPT. With respect to the third research question about participant's satisfaction with CAPT, descriptive statistics such as means and standard deviations were used to represent participant feedback. Cohen's d was also adopted to examine the effect size of differences between members of the two groups. Furthermore, the correlation between participant's satisfaction with CAPT and their development of pronunciation in English was answered with correlational analysis of each participant's difference of his/her first and last performance on MyET (i.e. the last score minus the first score) and the point he/she obtained from making response to the questionnaire.

\section{Results}

Preliminary to further panel design analysis, the appropriateness of its application to the present research was examined. The variables (Group and Satisfaction) at the intra-individual level, which aims to explore the individual's trajectory of performance in pronunciation and the inter-individual level, were included. Afterwards, the variances at the intra-individual level are examined using a random effects ANOVA model, which can be used to analyse individual variations in the outcome variable but excludes the time variable. The detailed information about the Growth Model is presented in the Table 1.

The information conveyed by the random effects ANOVA model indicates the appropriateness of the panel design because of the high interclass correlation coefficient (ICC $=0.65$ ), which is a measure of the amount of variance in the outcome that can be attributed to inter-individual differences (Raudenbush \& Bryk, 2002). Furthermore, this model specifies that during the 16-month research period, the average score of all participants was 58.89 out of 100, and that all participants made significant progress in English pronunciation during this period $(\mathrm{p}=0.00)$. Therefore, predictor variables can be added to the intercepts and slopes to better predict this variable. The random coefficient model was used to analyse the regression at the intra-individual level 
Table 1. Growth Model of Participant's Development of English Pronunciation and Satisfaction with ASR-based CAPT

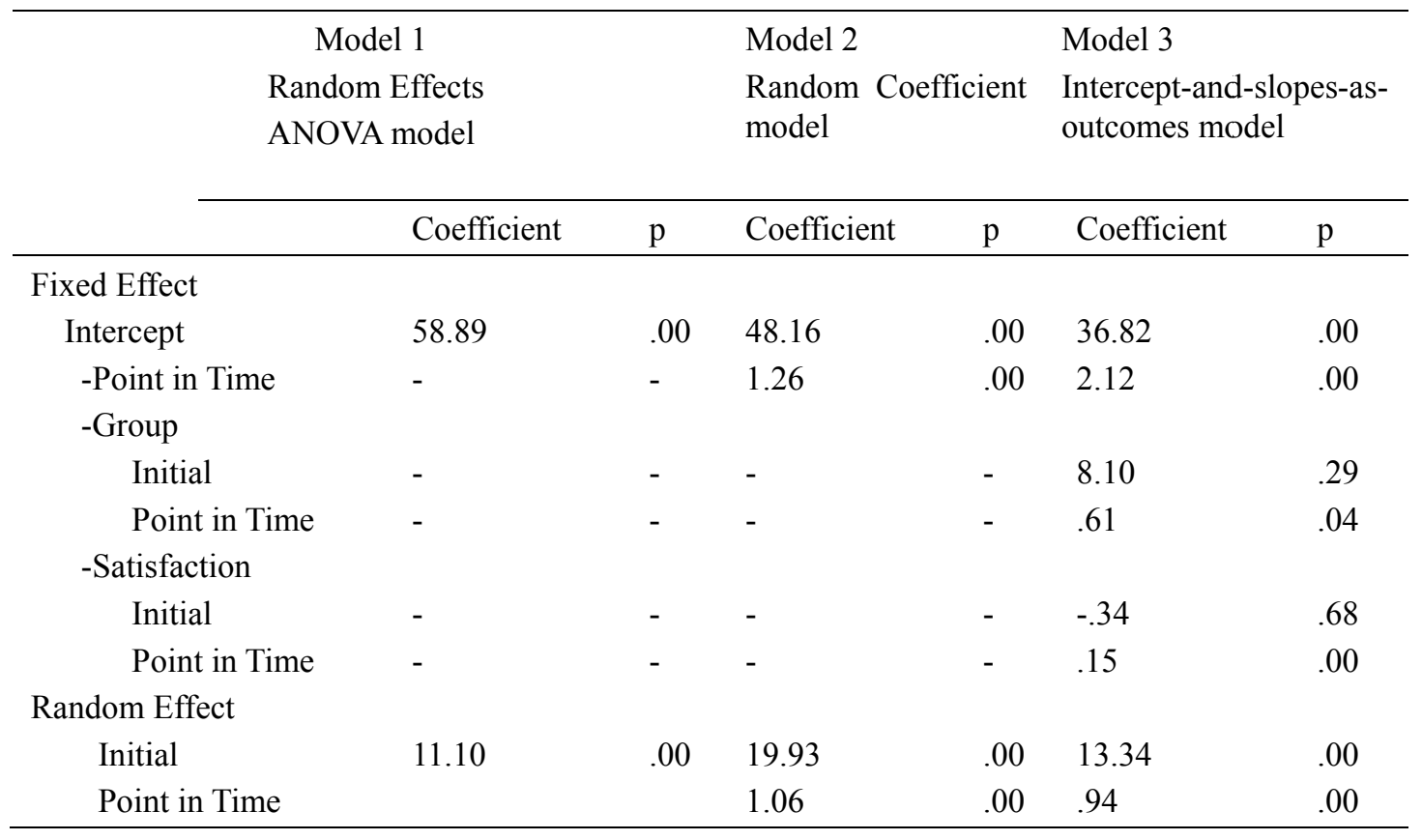

The random coefficient model indicates that the average score for the initial performance of all of the participants on CAPT was 48.16. The differences in an individual participant's initial performance and development over 16 months were both significant $(p=0.00)$. Therefore, it is suitable to include all variables at the intra-individual and inter-individual levels to obtain comprehensive results as the intercept-and-slopes-as-outcomes model

According to this comprehensive model, participant satisfaction with CAPT did not significantly differ at the beginning of the present research $(p=0.68>0.05)$. When the time variable was accounted for, satisfaction changed significantly between the two groups (coefficient $=0.15, \mathrm{p}=0.00$ ). The average development of pronunciation in English in the experimental group was 2.12 , which is also statistically significant $(\mathrm{p}=0.00)$. Furthermore, the group's average development was significantly higher than that of the control group (coefficient $=0.61, \mathrm{p}=0.04$ ).

In order to further explore the participant's perceptions of the effect of corrective feedback on individual participant's performance on the 16 tests, two focus-group interviews were undertaken. Most of the ten interviewees indicated that the corrective feedback provided them with constructive, helpful, and timely information about the problems that needed to be fixed in pronunciation. They credited CAPT for their improvement in pronunciation. For example, Student \#3 stated, 'I personally think CAPT is really helpful to me in terms of pronunciation training because it can spot my problems right away and also help me to fix them...' Further, Student \#5 noted the following: 'Thanks to this CAPT system, I have become aware of the correct position of the vocal organs... when I am speaking a sentence, I pay much attention to the intonation and the stress...' 


\section{Ml Macrothink}

International Research in Education

ISSN 2327-5499

2016, Vol. 4, No. 1

Participants who did not make comparatively salient progress through practice with ASR-based CAPT acknowledged the functionalities of MyET in helping them with pronunciation training, such as visualising the similarities and differences between their pronunciation and the virtual tutor. However, they also brought up some important points, which may concern practitioners who plan to apply it in pronunciation training. For example, Student \#9 indicated that motivation and self-efficacy was a more critical issue to him, and his statement was supported by Student \#6 and Student \#10, who reported that 'MyET was quite fun but my problem is that I don't think I have the talent in languages. Sometimes I just could not the differences between my pronunciation and other's...Nevertheless, the visualisation function was indeed a good one but I personally think I cannot maximise its functionality because my own problem...'

To measure participant's satisfaction with CAPT, their answers to a ten-item questionnaire were collected for statistical analysis. The descriptive statistics are presented in Table 2.

Table 2. Descriptive Information regarding Participant Satisfaction with CAPT

\begin{tabular}{|c|c|c|c|c|c|c|c|}
\hline & \multicolumn{2}{|l|}{ Experimental Group } & \multicolumn{2}{|c|}{ Control Group } & \multirow[t]{2}{*}{ t-value } & \multirow[t]{2}{*}{$\mathrm{p}$} & \multirow{2}{*}{$\begin{array}{l}\text { Cohen's } \\
\text { d }\end{array}$} \\
\hline & $\mathrm{M}$ & SD & $\mathrm{M}$ & SD & & & \\
\hline Satisfaction & 13.72 & 3.64 & 6.75 & 3.00 & 4.00 & .00 & 2.09 \\
\hline
\end{tabular}

The results indicate that the experimental group experienced significantly higher satisfaction levels than the control group (13.72 and 6.75 respectively on a scale of -20 to $20, p=0.002$ ). Furthermore, the large effect size (Cohen's $d=2.09$ ) demonstrates the treatment effect (Becker, 1999), which indicates that experience with ASR-based CAPT enhanced participants' satisfaction.

The correlational analysis between each participant's satisfaction with CAPT and his/her development of English pronunciation is reported in Table 3.

Table 3. Correlation Analysis between Participant's Satisfaction with CAPT and Their Development of English Pronunciation

\begin{tabular}{|c|c|c|}
\hline & Satisfaction with CAPT & Development of English Pronunciation \\
\hline Satisfaction with CAPT & & $.90 * *$ \\
\hline Sig. (two-tailed) & & .000 \\
\hline
\end{tabular}

Pearson product-moment correlation coefficient shows a statistically strong correlation between these two variables $(\gamma=0.90, p<0.00)$. This finding suggests that the more an individual is satisfied with ASR-based CAPT, the greater progress he/she may attain in English pronunciation. 


\section{Discussion}

This study aimed to examine the long-term effects of ASR-based CAPT on the development of English pronunciation among EFL learners. Longitudinal data were collected over a 16-month period for LGC analysis. The results support and complement prior cross-sectional research, such as Trofimovich and Baker (2006), who emphasised that the more access a L2 learner has to the target language, the better pronunciation he/she would possibly attain. In an EFL context in which learner accessibility to authentic English is limited, CALL appears to be an adequate alternative. Additionally, this study demonstrates that CAPT has long-term effects on the development of pronunciation in English by EFL learners as a result of successful facilitation of EI by ASR-based CAPT. This study also provides evidence that pronunciation training with visualisation technology can benefit EFL learners (Kim, 2012; Levis \& Pickering, 2004). Visualised corrective feedback enabled participants to directly compare their productions with model utterances, and such crucial distinctions are likely to be helpful to learners (Derwing \& Munro, 2005; Neri, Cucchiarini, Strik, \& Boves, 2002), as confirmed in this study. The negative correlation between the quantity of corrective feedback individual participants received and their pronunciation performance implies that the more the individual's pronunciation improved, the less the amount of corrective feedback he/she would need. The corrective feedback that participants receive at the segmental and supra-segmental levels can improve pronunciation because 'students should learn how to distinguish content words from function words before learning how to pronounce sentence-stress properly...L2 and ESL teachers are urged to teach English intonation with much emphasis on communicative purposes and functions and in a socially-interactive setting' (Yangklang, 2013, p. 451). Such a statement may contradict Chen et al. (2014) and Lazar, Jones, Hackley, and Shneiderman (2006), who found that CAPT did not improve the pronunciation of EFL learners and argued that EFL learners become depressed as a result of the continual detection of their mistakes by a speech recognition system. Evidently, depression was not an issue in the present research. Although participants received continuous feedback on their imperfect pronunciation, they did not appear to be affected by it.

Additionally, in previous studies, ASR-based feedback consisted only of simple accept/reject responses. However, in this study, corrective feedback was provided, including the phonetic attributes of a particular sound and an animated demonstration of the speech organs, which was found to be important in the construction of an inter-language (Lyster et al., 2013; de Vries et al., 2014). Therefore, EFL learners' EI, accompanied by corrective feedback provided by ASR-based CAPT, can have long-term effects on pronunciation development. Learners expect to receive more corrective feedback than teachers believe they should provide (Lyster et al., 2013). However, Brown (2009) suggested that corrective feedback may impede the flow of communication and thus should be limited. Future research should address this issue in details. In addition, MyET provided participants with a large amount of insightful information, for example, about the intonation of their output at the discourse level. Such features can be substantially helpful in improving the intelligibility of EFL learner's spoken English. 
Additionally, the experimental group exhibited greater satisfaction with ASR-based CAPT than the control group. The effect of CAPT was significant, owing to the large effect size. The present study also indicates that such satisfaction is positively associated with improved pronunciation. This result supports Son's (2007) research, which found positive attitudes among students toward CALL following the treatment. Nevertheless, it is possible that the repetition effect is the reason that the experimental group outperformed the control group in the development of pronunciation. Participants with more opportunities to use ASR-based CAPT for EI would naturally be more familiar with the system.

\section{Pedagogical Implications and Limitations}

Given the findings of this study, the pedagogical application of CAPT has several implications. Simply employing CAPT will not naturally result in better pronunciation in EFL learners; sometimes, it may even be counterproductive in real interactions (Derwing \& Munro, 2005). Caution is advised when the application of CAPT for EFL learners is to be optimised. Furthermore, the visualisation of supra-segmental production enables EFL learners to have a better understanding about the prosodic features of English sentences (Levis \& Pickering, 2004).

Furthermore, EI involves more than simply repetition and drill. On the contrary, learners are encouraged to emphasise their interactions with CAPT, as Hsieh et al. (2013) have proposed. In such circumstances, corrective feedback is essential, particularly when certain errors that are difficult for learners to locate occur in the inter-language (Ellis, 2008; Lyster et al., 2013). More importantly, the corrective feedback provided by CAPT should be explicit for EFL learners (Chiu et al., 2007). It is suggested that visualised corrective feedback will benefit EFL learners in pronunciation training.

This study has several limitations, and caution is advised in interpreting the results. The first limitation is the sample size, as we lacked a pool of subjects that was sufficiently large to include EFL learners of various backgrounds. Another limitation is that the CAPT system adopted in the study was designed using only North American English accents, which may aid the pronunciation training of EFL learners but also limit learner's opportunities to receive input in other accents, such as British accent or other non-North American accents. Future research should include additional accents in CAPT and examine which accents facilitate or hinder EFL learner pronunciation training.

\section{Conclusion}

Pronunciation is of great importance in successful communication, but the teaching of pronunciation is usually given the least attention by EFL teachers. Additionally, elicited imitation seems to be beneficial for language learning, particularly in pronunciation training. Therefore, conducting EI with ASR-based CAPT is a feasible alternative in an EFL context where the availability of native English teachers is limited. In this paper, the long-term effectiveness of EI administered with ASR-based CAPT was examined. A latent growth curve, covering a 16-month period of ASR-based CAPT, was established to examine the trajectory of individual participant's pronunciation in English. EFL learners who had 
opportunities to practice EI with ASR-based CAPT significantly improved more so than those who did not. The study provides empirical evidence, with strong statistical power, of the long-term effectiveness for EFL learners of EI administered with ASR-based CAPT. Corrective feedback provided through CAPT was considered to be helpfiul to EFL learner's development of English pronunciation, which was confirmed by correlational analysis, ANCOVA, and qualitative data.

Additionally, EFL learner's satisfaction with CAPT also matters in the development of pronunciation in English. The relationships among the proposed variables, namely EFL learner's opportunities to practice EI with ASR-based CAPT, their satisfaction, and their English pronunciation, are revealed to be positive in this study. Ultimately, this study extends our current understanding of the applicability of ASR-based CAPT on EFL learner's pronunciation training and provides applied linguists and language instructors with empirical evidence on the possible interdependence of the proposed variables.

\section{Acknowledgement}

The research project is financially supported by the Ministry of Science and Technology, Taiwan (MOST 103-2511-S-328-001-MY2).

\section{References}

Almekhlafi, A. G. (2006). The effect of Computer Assisted Language Learning (CALL) on United Arab Emirates English as a foreign language (EFL) school student's achievement and attitude. Journal of Interactive Learning Research, 17(2), 121-142.

Barr, D., Leakey, J., \& Ranchoux, A. (2005). Told like it is! An evaluation of an integrated oral development pilot project. Language, Learning \& Technology, 9(3), 55-78.

Bauer, M. W., \& Gaskell, G. (2000). Qualitative researching with text, image and sound: A practical handbook for social research. Thousand Oaks: Sage.

Breitkreutz, J., Derwing, T. M., \& Rossiter, M. J. (2002). Pronunciation teaching practices in Canada. TESL Canada Journal, 19, 51-61.

Brown, A. (2009). Student's and teacher's perceptions of effective foreign language teaching: A comparison of ideals. The Modern Language Journal 93(1), 46-60. http://dx.doi.org/10.1111/j.1540-4781.2009.00827.x

Celce-Murcia, M., Brinton, D. M., \& Goodwin, J. M. (2010). Teaching pronunciation hardback with audio CDs (2): A Course Book and Reference Guide. Cambridge: Cambridge University Press.

Chen, J., Belkada, S., \& Okamoto, T. (2004). How a web-based course facilitates acquisition of English for academic purposes. Language Learning \& Technology, 8(2), 33-49.

Chen, L., Zhang, R., \& Liu, C. (2014). Listening strategy use and influential factors in Web based Computer Assisted Language Learning. Journal of Computer Assisted Learning, 30(3), 207-219. http://dx.doi.org/10.1111/jcal.12041 


\section{Macrothink}

International Research in Education

ISSN 2327-5499

2016, Vol. 4, No. 1

Chiu, T. L., Liou, H. C., \& Yeh, Y. (2007). A study of web-based oral activities enhanced by automatic speech recognition for EFL college learning. Computer Assisted Language Learning, 20(3), 209-233. http://dx.doi.org/10.1080/09588220701489374

Chun, D. (2007). Come ride the wave: But where is it taking us? CALICO Journal, 24(2), 239-252.

Cook, K., \& McGhee, J. (2011). Elicited imitation for prediction of OPI test scores. Proceedings of the Sixth Workshop on Innovative Use of NLP for Building Educational Applications, 30-37.

Darabad, A. M. (2014). Corrective feedback interventions and EFL learner's pronunciation: A case of $-\mathrm{s}$ or $-\mathrm{es}$ ending words. International Journal of Learning \& Development, 4(1), 40-58. http://dx.doi.org/10.5296/ijld.v4i1.5010

de Vries, B. P., Cucchiarini, C., Bodnar, S., Strik, H., \& van Hout, R. (2014). Spoken grammar practice and feedback in an ASR-based CALL system. Computer Assisted Language Learning, (ahead-of-print), 1-27.

Derwing, T. M., \& Munro, M. J. (2005). Second language accent and pronunciation teaching: A research - based approach. TESOL Quarterly, 39(3), 379-397. http://dx.doi.org/10.2307/3588486

Ellis, R. (2008). Explicit knowledge and second language learning and pedagogy. In J. Cenoz \& N. H. Hornberger (Eds.), Encyclopedia of language and education: 6: Knowledge about language (pp. 143-153, 2nd ed.). New York: Springer. http://dx.doi.org/10.1007/978-0-387-30424-3_145

Felps, D., Bortfeld, H., \& Gutierrez-Osuna, R. (2009). Foreign accent conversion in computer assisted pronunciation training. Speech Communication, 51(10), 920-932. http://dx.doi.org/10.1016/j.specom.2008.11.004

Field, J. (2005). Intelligibility and the listener: The role of lexical stress. TESOL Quarterly, 39(3), 399-423. http://dx.doi.org/10.2307/3588487

Francis, D. J., Fletcher, J. M., Stuebing, K. K., Davidson, K. C., \& Thompson, N. M. (1991) Analysis of change: Modelling individual growth. Journal of Consulting and Clinical Psychology, 59(1), 27-37. http://dx.doi.org/10.1037/0022-006X.59.1.27

Gilakjani, A. P. (2011). A study on the situation of pronunciation instruction in ESL/EFL classrooms. Journal of Studies in Education, 1(1), E4. Retrieved May 20, 2014, from http://www.macrothink.org/journal/index.php/jse/article/viewFile/924/746

Godwin-Jones, R. (2009). Emerging technologies speech tools and technologies. Language Learning \& Technology, 13(3), 4-11.

Graham, C. R., Lonsdale, D., Kennington, C. R., Johnson, A., \& McGhee, J. (2008). Elicited lmitation as an oral proficiency measure with ASR scoring. In LREC. http://repository.dlsi.ua.es/242/1/pdf/409_paper.pdf 


\section{Macrothink}

International Research in Education

ISSN 2327-5499

2016, Vol. 4, No. 1

Hincks, R. (2003). Speech technologies for pronunciation feedback and evaluation. ReCALL, 15(1), 3-20. http://dx.doi.org/10.1017/S0958344003000211

Hismanoglu, M., \& Hismanoglu, S. (2010). Language teacher's preferences of pronunciation teaching techniques: traditional or modern? Procedia Social and Behavioral Sciences, 2, 983-989. http://dx.doi.org/10.1016/j.sbspro.2010.03.138

Hsieh, K. T., Dong, D. H., \& Wang, L. Y. (2013). A preliminary study of applying shadowing technique to English intonation instruction. Taiwan Journal of Linguistics, 11(2), 43-66.

Jepson, K. (2005). Conversations and negotiated interaction in text and voice chat rooms. Language Learning \& Technology, 9(3), 79-98.

Jenkins, J. (2002). A socio linguistically based, empirically researched pronunciation syllabus for English as an international language. Applied Linguistics, 23, 83-103. http://dx.doi.org/10.1093/applin/23.1.83

Jessop, L., Suzuki, W., \& Tomita, Y. (2007). Elicited imitation in second language acquisition research. The Canadian Modern Language Review/La Revue Canadienne des Langues Vivantes, 64, 1 (September), 215-238. http://dx.doi.org/10.3138/cmlr.64.1.215

Kim, A. (2012). Investigating the effectiveness of Computer Assisted Language Learning (CALL) in improving pronunciation: A case study. Multimedia-Assisted Language Learning, 15(3), 11-33.

Lambacher, S. (1999). A CALL tool for improving second language acquisition of English consonants by Japanese learners. Computer Assisted Language Learning, 12(2), 137-156. http://dx.doi.org/10.1076/call.12.2.137.5722

Lazar, J., Jones, A., Hackley, M., \& Shneiderman, B. (2006). Severity and impact of computer frustration: A comparison of study and workplace users. Interacting with Computers, 18(2), 187-207. http://dx.doi.org/10.1016/j.intcom.2005.06.001

Levis, J. (2007). Computer technology in teaching and researching pronunciation. Annual Review of Applied Linguistics, 27, 184-202. http://dx.doi.org/10.1017/S0267190508070098

Levis, J., \& Pickering, L. (2004). Teaching intonation in discourse using speech visualization technology. System, 32, 505-524. http://dx.doi.org/10.1016/j.system.2004.09.009

Levy, Y. (2007). Comparing dropouts and persistence in e-learning courses. Computers \& Education, 48, 185-204. http://dx.doi.org/10.1016/j.compedu.2004.12.004

Lindlof, T. R., \& Taylor, B. C. (2002). Qualitative Communication Research Methods (2nd Ed.). Thousand Oaks, CA: Sage.

Lyster, R., Saito, K., \& Sato, M. (2013). Oral corrective feedback in second language classrooms. Language Teaching, 46, 1-40. http://dx.doi.org/10.1017/S0261444812000365

Mack, N., Woodsong, C., MacQueen, K. M., Guest, G., \& Namey, E. (2005). Qualitative 
research methods: a data collector's field guide. Retrieved on March $24^{\text {th }}, 2015$ from http://www.fhi360.org/sites/default/files/media/documents/Qualitative\%20Research\%20Meth ods\%20-\%20A\%20Data\%20Collector\%27s\%20Field\%20Guide.pdf

Marasco, O. (2011). Can Intonation Be Imitated? Simultaneous production vs elicited lmitation of Wh-questions. Proceedings of the 2011 annual conference of the Canadian Linguistic Association.

McDonough, K. (2005). Identifying the impact of negative feedback and learner's responses on ESL question development. Studies in Second Language Acquisition, 27(1), 79-103. http://dx.doi.org/10.1017/S0272263105050047

Mich, O., Neri, A., \& Giuliani, D. (2006). The effectiveness of a Computer Assisted pronunciation training system for young foreign language learners. Proceedings from $C A L L$ 2006. Antwerp, Belgium, 135-143.

Munsakorn, N. (2012). Learner's satisfaction on CALL. Mediterranean Journal of Social Sciences, 3(11), 165.

Murphy, J. M. (2014). Intelligible, comprehensible, non-native models in ESL/EFL pronunciation teaching. System, 42, 258-269. http://dx.doi.org/10.1016/j.system.2013.12.007

Nair, R., Krishnasamy, R., \& De Mello, G. (2006). Rethinking the teaching of pronunciation in the ESL classroom. The English Teacher, 35, 27-40.

Neri, A., Cucchiarini, C., \& Strik, H. (2006). ASR corrective feedback on pronunciation: Does it really work? Proceedings from ICSLP 2006, 1982-1985. Pittsburgh, USA.

Neri, A., Cucchiarini, C., \& Strik, H. (2008). The effectiveness of Computer-based speech corrective feedback for improving segmental quality in L2 Dutch. ReCALL, 20(2), 225-243. http://dx.doi.org/10.1017/S0958344008000724

Neri, A., Cucchiarini, C., Strik, H., \& Boves, L. (2002). The pedagogy-technology interface in computer assisted pronunciation training. Computer Assisted Language Learning, 15, 441467. http://dx.doi.org/10.1076/call.15.5.441.13473

Neri, A., Mich, O., Gerosa, M., \& Giuliani, D. (2008). The effectiveness of Computer Assisted pronunciation training for foreign language learning by children. Computer Assisted Language Learning, 21(5), 393-408. http://dx.doi.org/10.1080/09588220802447651

Osgood, D. W., \& Smith, G. L. (1995). Applying Hierarchical Linear Modelling to extended longitudinal evaluations: The boy's town follow-up study. Education Review, 19(3), 3-38.

Raudenbush, S. W., \& Bryk, A. S. (2002). Hierarchical linear models: Applications and data analysis methods (Advanced quantitative techniques in the social sciences) (2nd ed.). Thousand Oaks, CA: Sage Publication.

Savin-Baden, M. \& Major, C. (2013). Qualitative Research: The essential guide to theory and practice. London: Rutledge. 


\section{Macrothink}

International Research in Education

ISSN 2327-5499

2016, Vol. 4, No. 1

Shek, D. T. L., \& Ma, C. M. S. (2011). Longitudinal data analyses using linear mixed models in SPSS: Concepts, procedures and illustrations. The Scientific World Journal, 11, 42-76. http://dx.doi.org/10.1100/tsw.2011.2

Son, J. B. (2007). Learner experiences in web-based language learning. Computer Assisted Language Learning, 20(1), 21-36. http://dx.doi.org/10.1080/09588220601118495

Stein, D. (2004). Course structure: Most important factor in student satisfaction. Distance Education Report, 8(3), 4.

Thomson, R. I. (2011). Computer Assisted pronunciation training: Targeting second language vowel perception improves pronunciation. CALICO Journal, 28(3), 744-765. http://dx.doi.org/10.11139/cj.28.3.744-765

Trofimovich, P., \& Baker, W. (2006). Learning second language supra-segmental: Effect of L2 experience on prosody and fluency characteristics of L2 speech. Studies in Second Language Acquisition, 28, 1-30. http://dx.doi.org/10.1017/S0272263106060013

Tsai, P. -H. (2006). Bridging pedagogy and technology: User evaluation of pronunciation oriented CALL software. Australasian Journal of Educational Technology, 22(3), 375-397.

Wang, X., \& Munro, M. J. (2004). Computer-based training for learning English vowel contrasts. System, 32(4), 539-552. http://dx.doi.org/10.1016/j.system.2004.09.011

Yangklang, W. (2013). Improving English stress and intonation pronunciation of the first year students of Nakhon Ratchasima Rajabhat University through E-learning. Procedia Social and Behavioural Sciences, 91, 444-452. http://dx.doi.org/10.1016/j.sbspro.2013.08.442 


\section{Appendix 1 Questionnaire}

1. I found my pronunciation very easy to be recognized by the system (i. e. MyET).

2. I found the system is able to make fair judgments on my pronunciation.

3. I can use 'tones' and 'intonation' of English effectively now.

4. I can use 'prominence' (sentence-level stress) of English effectively now.

5. My use of rhythm in English is much effective now.

6. My use contrastive stress in English effectively now.

7. My 'word endings' of English are clear now.

8. The pacing of my speech in English has improved now.

9. I am satisfied with this ASR-based CAPT system.

10. My oral proficiency of English has improved with the help of this system.

Strongly disagree $=-2$

Disagree $=-1$

Neutral $=0$

Agree $=1$

Strongly agree $=2$

\section{Copyright Disclaimer}

Copyright reserved by the authors.

This article is an open-access article distributed under the terms and conditions of the Creative Commons Attribution license (http://creativecommons.org/licenses/by/3.0/). 